\title{
THE MYTH OF THE NON-CONSUMPTIVE USER
}

RIAN WILKES, Nanaimo Naturalist Club, Box 125, Nanaimo, British Columbia V9R 5K 4

DITOR'S NOTE: This ariticle has een condensed from the Octoberecember 1977 issue (Vol. 91, No. 4) of he Canadian Field-Naturalist.

It is easy to understand why creational hunting and fishing are onsidered consumptive. Living rganisms are physically removed om the scene, and consequeces are pparent when populations of game ecline. Certain conservation groups $r$ individuals in them often rail gainst consumptive forms of creation. Other groups recognize nd accept the consumptive nature of heir activity, arguing that they merely rop off some sort of "harvestable irplus." Rod and gun clubs, rifle ssociations and other groups are in is category. No matter what one's articular attitude toward hunting and shing is, there is general agreement lat these are consumptive activites. hey are closely regulated in terms of ag limits or in the number of licensed articipants. These controls derive om the recognition of the conimptive nature of the acitivity and e constant with conventional anagement techniques.

By contrast, hiking or back-packing, ghtseeing, general tourism and imping in parks, nature study, nature hotography, and picnicking are early regarded as non-consumptive the resource base. These activities not seem to remove living ganisms from the scene. They are garded as healthful pursuits that are enign in terms of the surrounding ndscape. Participants in these acvities are regarded as noninsumptive users of outdoor creation resources, and con- sequently there are few controls governing their numbers or behavior.

No one can possibly guess the total number of people who visit unorganized facilities. The point is that non-consumptive users are present in far greater numbers than consumptive users. For example, in 1975, the number of hunters and anglers in British Columbia was about 512,000 . No figures are avialable for the numbers of hunter or angler days for that year, but they could not possibly approach the 8.7 million day and overnight visits to provincial parks in British Columia for the same year. In addition, the British Columbia Forest Service provides unsupervised camping facilities throughout the province, and cannot estimate the number of people who use them. Both Crown Zellerbach and MacMillan Bloedel who provide limited facilities in their timber limits estimate the yearly visitation to be in the tens of thousands.

These are estimates for British Columbia alone, with a population of 2.5 million. We would surmise that the total number of "non-consumers" ranging across the landscape of all provinces and territories is staggering They have become big business, and a big problem.

The concept of the non-consumptive user of outdoor recreation resources is false. Because the notion of the nonconsumptive user has been so widely accepted, many serious errors have been made in land-use planning and in the philosophy of the conservation movement. Here is a case in which a comfortable myth has been applied as a principle of land use, and as a result 
some of the major objectives of the conservation movement are in jeopardy.

If so-called non-consumptive activities are not so benign, then we had better acknowledge this and get down to the serious business of reassessing our priorities. One of the major objectives of the conservation movement is the preservation of natural landscapes and habitats. We have focused on gaining legislative protection for them without very seriously addressing the question of what happens to them next. In fact, the chief argument used in support of natural area preservation, except ecological reserves, is the benefit that supposedly accrues to the public in terms of recreation.

Non-consumptive users do consume recreation resources along spatial, visual, and physical dimensions. They trample and rearrange vegetation patterns, disturb wildlife, and are the chief distributors of refuse across the land.

Spatial consumption simply means recreation consumes space. In a small park like Ivy Green Provincial Park, south of Nanaimo on Vancouver Island (62 acres), the act of providing for the accommodation of nonconsumptive users has succeeded in directly consuming three-quarters of the habitat, and this in a park which has statutory protection from impairment. In this example, the visitors do not directly remove organisms from the scene. The government does it for them, with our blessings.

Visual consumption means that large numbers of people consume solitude. Crowds in any particular area can build to the point where the scenic amenities of the site are completety lost by the presence of too many people.

Another aspect of visual consumption is the visual impact humans have on wildlife. There are a number of wildlife species that seem to require privacy from human intrusion in order to thrive in their respective ecosystems. In these cases the presence of people may not be directly consumptive, but in the long run the result is the same.

Beyond requirements for access and accommodation on recreational landscapes lies the problem of direct physical impact. Studies have shown that in certain environments, such as forested area with a well-developed ground cover, very severe impacts occur with the lightest use, and that physical impact is cumulative over ? period of time. Even light and oc casional use of an area for hiking or nature study can have its effect ir time.

The direct crushing of vegetation by trampling is one factor that favors the replacement of natural vegetation by non-native basal rosette-type plant such as plantain or hawkweed. Soi compaction caused by human treading retards the growth of trees, perhap killing them. Forest duff can bs pulverized, the soil denuded, the ground can become puddled and down-slope erosion can occur. The long-term effects of these impacts are visibly and seriously to alter the original vegetation patterns and associations in a manner that norma plant succession would not. Fur thermore, wildlife that requires specia vegetational habits will be affected.

Members of naturalist clubs are often the worst offenders in unique o highly sensitive habitats. These ar areas we actively seek because of thei high interest value. We tramp aroun in bogs, marshes, alpine meadows, an gull colonies, content in our non consumptive status. Increasin numbers of natural food buffs ar systematically harvesting edible wilc nature.

The accumulation of garbage an 
most serious consumers, simply by virtue of their numbers, by what they do, and where they do it.

We must accept that the notion of non-consumptive use is a myth. There is simply no such thing as a nonconsumptive user.

At least three implications come to mind if we are to reject the idea of non-consumptive users. We must construct strict rules guiding our behavior when visiting natural landscapes. We must adopt a new attitude and approach to land-use planning as it applies to recreational landscapes.

We would recommend that clubs make an effort to travel to special spots only very occasionally; and when they do, they should travel in small groups. Choose places to go at a time of year when you'll do the least damage, and then stay on established pathways in small groups. Identify plants where they are without picking bits off to check at home. We know a few "naturalists" who crash around looking for bird nests, and photographers who tear away the foliage for the proper camera angle.

Controls on behavior extend from the voluntary action of clubs to the mandatory restrictions of government agencies. Strict visitor controls appropriate in large parks include party size limits, the use of burnable containers only, and the use of stoves rather than fires where natural wood is at a premium. The ideal situation would entail licensing all back-country users and regulating their numbers through a permit system. The licensing procedure has a double benefit. It allows agencies to know how many users there are, and it could mean a skills test prior to licensing. A skills test is very important because ignorant and unskilled people are using natural landscapes more and more, and they do the most damage.
If we reject the idea of the non consumptive user, and yet recognize the importance of landscap preservation, we can hardly endorse parks as the appropriate vehicle fo preservation, because parks ar justified and developed for thei recreation potential.

This does not mean we should rejec the idea of parks, but rather encourag governments to become serious abou their stated purpose of preservin unimpaired landscapes. Neithe should we reject the idea of people $i$ parks, because there are regulator mechanisms available to limi resource consumption by tourists an others. But we must dismiss the ide that landscapes, and the communitie of life on them, can only be preserve in parks, and that the rationale preservation is recreation.

We should hold that the landscape and their internal dynamics should $b$ preserved solely because they ar there, for their own sake, and becaus they have a right to exist. If $w$ recognize the consumptive nature all recreational land uses, and al really concerned about landscap preservation, then we should reje conventional land-use planning favor of non-use planning.

A new theory of non-use plannir can be generated from a thoroug understanding of the nature resource consumption recreationists. It would involve th identification of physical carryir capacities on natural landscapes. would centre around strict controls the numbers, and behavior of $p_{c}$ ticipants in supposedly no consumptive pursuits. It would pla preservation as the top priority inste of use. Finally, it would emphasize th non-human nature exists for its ov sake, and that the accommodation people in it is not a matter of $\mathrm{COI}$ promise but rather one of integration 